\title{
Online Identification on Operational Risks of the Second and Third Defense Line of UHVDC Sending-End Power Grid
}

\author{
Rui $\mathrm{Yu}^{1}$, Zhen Xiang ${ }^{2}$, Jun Xiong ${ }^{1}$, Jianhui GU², Fan Tang ${ }^{1}$, Xiaoyu Wang ${ }^{2}$ and Xiongfei Wang ${ }^{2}$ \\ ${ }^{1}$ Southwest China Electric Power Control Center, Chengdu 610000, Sichuan, China \\ ${ }^{2}$ NARI Group Corporation / State Grid Electric Power Research Institute, Nanjing 211106, Jiangsu, China
}

\begin{abstract}
The paper analyzed the potential safety and stability control risk of the southwest power grid, presented the general online identification framework for operational risks of the second and third defense line of UHVDC sending-end power grid, elaborated the key techniques for realizing the aforementioned functions, including security control strategy/system protection strategy modelling, high frequency cutting generator strategy modelling, conflict detection for the control measures of the second and third defense line, practicability assessment method for security control strategy/system protection strategy, practicability assessment method of high frequency cutting generator strategy and other technologies. According to the actual application conditions of the southwest power grid, the system may provide dispatching users with more comprehensive Online identification for the operational risks the second and third defense line as well as discover the potential safety hazards and risks during operation of the power grid.
\end{abstract}

\section{Introduction}

Southwest power grid enjoys abundant water resources. With the constructions of series of UHVDC transmission projects, transportation scale of Southwest power grid has been further increased; however, the changes in the abundance of hydropower output and the impact of natural disasters on the transmission channel are making the southwest power grid transmission power, grid operation, security and stability characteristics complicated and changeable [1-7].In order to insure safe, stable and economic operation of the large power grid, a great amount of regional security and stability control systems and devices has been equipped in southwest power grid. However, the current security and stability control system is for solving local problems only and still has the problems of simplified control measures, lack of integral evaluation, insufficient coordination control and other defects in terms of UHVDC blocking fault. Therefore, the AC/DC coordinated control system shall be constructed in southwest power grid to solve the problems of safety and stability in the whole network [8-10]. Meanwhile, high frequency cutting generator shall be reasonably equipped in the UHVDC sending-end power grid to avoid the risk of high-frequency power grid under serious failures. Therefore, accurate perception of the online running status of the second and third defense line of southwest power grid plays an extremely important role in comprehensive understanding of the safe and stable operational level of power grid [11-13].

Current researches have achieved abundant results in aspects of online monitoring and management of the second and third defense line, among which, the reliability of the stability control system on various dimensions, such as the general framework, running mode, control mode, were verified in literature [14]. Online monitoring and management on the security and stability control system and device were performed in literature [15-17] via constructing safety control integrated management system in the control center, validity and rationality were evaluated, and multiple DC emergency control, pumping, energy storage, pump switching and other control strategies of multiple control resources were presented in literature [18] and the function of integrated monitoring and early warning of the high frequency cutting generator in the third defense line was also proposed in literature [19] to effectively improve monitoring capability of the third defense line. However, the aforementioned researches are aimed at the monitoring of the second and third defense line instead of performing integrated monitoring and analysis on the second and third defense line, and it is unable to comprehensively identify operational risks in the second and third defense line.

Under the above context, the paper proposed the general online identification framework for the operational risks of the second and third defense line of the UHVDC sending-end power grid and elaborated key techniques, such as security control strategy/system protection strategy modelling, high frequency cutting generator strategy modelling, conflict detection for the control measures of the second and third defense line, practicability assessment method of security control strategy/system protection strategy, practicability assessment method of high frequency cutting generator strategy, performed comprehensive analysis on various

xiangzhen@sgepri.sgcc.com.cn 
monitoring information of the second and third defense line to push the messages of abnormal device, practicability assessment result, strategy check result, module conflict and other risk information to the personnel in charge of dispatching and operation. Furthermore, the paper also introduced the application of the technique in southwest power grid, and described the supporting role of the system on safe and stable operation of power grid.

\section{General framework}

Based on the AC/DC coordinated control system, the online monitoring system of the second and third defense line adopt the software, hardware and information resources of the current security and stability control system, integrate the security control strategy/system protection strategy model constructed by southwest power grid security control system/system protection system and combine the third defense line strategy model to analyze the existence of controlled quantity conflict between identification security control strategy/system protection strategy and the third defense line strategy.

The paper also performed practicability assessment method of security control strategy/system protection strategy, and practicability assessment method of high frequency cutting generator strategy, verified if the onduty strategy can be sufficiently implemented and provided all-around risk identification information to the personnel in charge of dispatching and operation. Refer to the following Fig 1 for detailed information about the general system framework.

\section{Dispatching}

personnel

Online identification on operational risks in

Various risk identification information

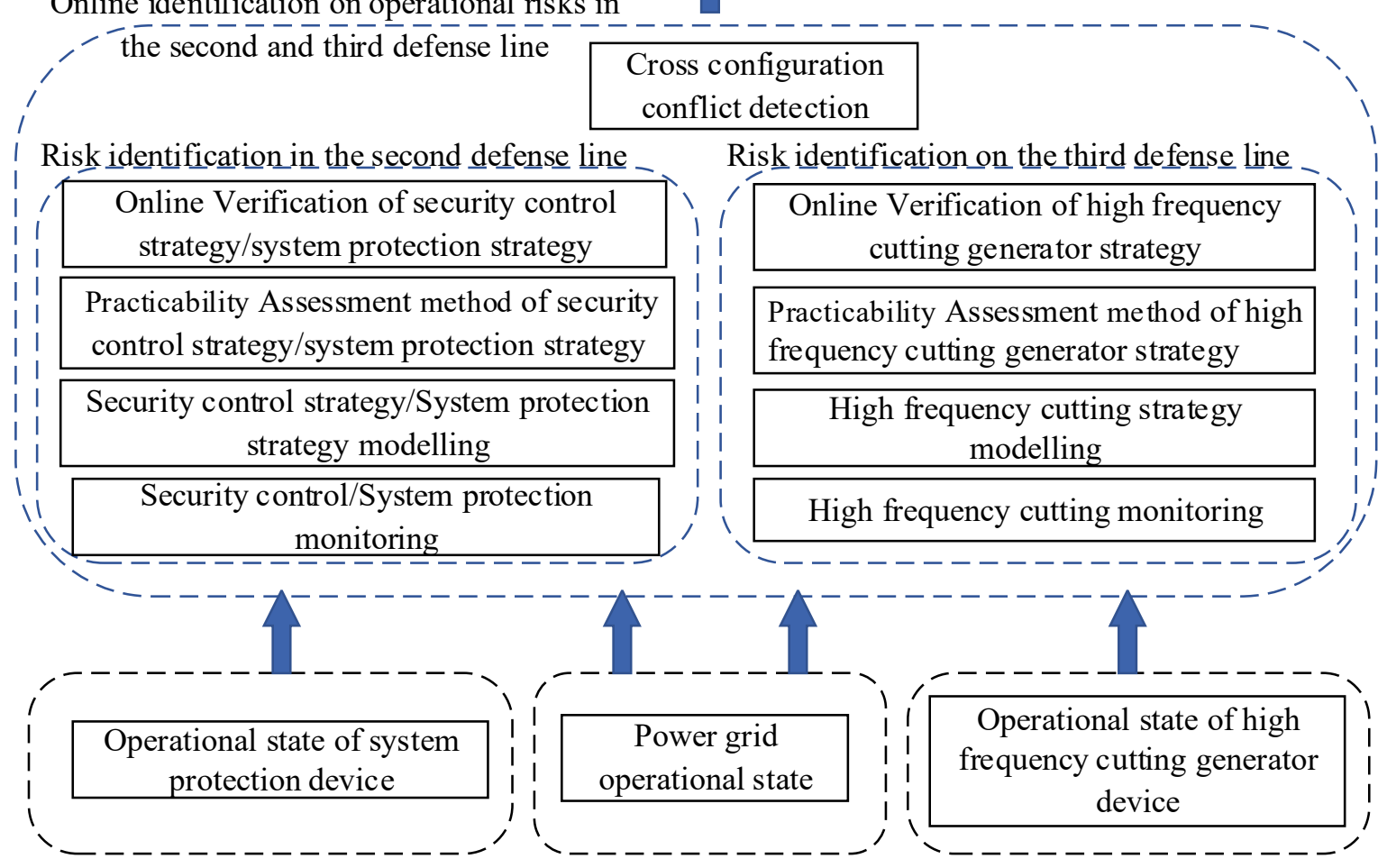

Fig. 1. General framework of online identification on operational risks of the second and third defense line of UHVDC sending-end power grid.

Main function modules: security control strategy/system protection strategy modelling, high frequency cutting generator strategy modelling, security control strategy/system protection monitoring, high frequency cutting generator monitoring, practicability assessment method of security control strategy/system protection strategy, practicability assessment method of high frequency cutting generator strategy modelling, cross configuration detection, online verification of security control strategy/system protection strategy, online verification of high frequency cutting generator.

The security control strategy/system protection strategy modelling module realizes unified description of security control device/system protection device and its strategy model through structured modelling, and designs reasonable data structure to facilitate simulation of device actions; high frequency cutting generator strategy modelling may realize uniform description of operational conditions and logic of the high frequency cutting generator via structured method; security control /system protection monitoring module includes the acquisition of operation conditions of the safety control device, alarm of abnormal or action events, calling and display of wave recording, identification of abnormal device and other risks of safe power grid operation; high frequency cutting generator monitoring mainly involves the acquisition of 
operation conditions of the high frequency cutting generator, monitoring of capacity information of the switchable unit, identification of abnormal high frequency cutting generator and other risks; the security control/system protection practicability assessment module assesses the enforceability status of the current policy according to the policy model and given the current grid operating conditions and the operating conditions of the security control device/system protection device, and assesses whether there is any irrelevant risk of the system protection policy; practicability assessment method of high frequency cutting generator strategy may make statistics on controllable quantity of the high frequency cutting generator within the area, judge if it may satisfy the requirement on desired controllable quantity of the annual allocation plan of high frequency cutting generator in southwest and evaluate if there exists inadequate controls risk in the high frequency cutting generator strategy; the security control/system protection online verification module performs static and transient safety verification of severe anticipated faults based on current policy identification; the high frequency cutting generator online verification module performs static and transient safety verification of severe anticipated faults based on current policy identification; cross configuration detection module may perform online identification according to control measures of various strategies, analyze if there exists cross conflict configuration and potential risk of controlled quantity reduction.

\section{Key technology}

\subsection{Security control strategy/System protection strategy modelling}

By means of comprehensive analysis on large amount of actual security control device/system protection device strategies, the paper analyzed key factors including organizational form of the security control strategy/system protection strategy, basic control logics, mode of distribution of the controlled quantity. Established the corresponding security control policy structured model [20-22], and realized the integrity modelling of the security control policy execution path based on the "coordinated control terminal - master station - sub-station - execution station". Refer to Fig 2 for detailed information.

The strategy is organized in the form of a quadratic table, and the control strategy is decomposed into five basic elements, summarizing four basic structural models of the control strategy: direct type, sequential type, cyclic type and optimal type, and designing hierarchical associated data structures to achieve the structural modelling of the strategy. The quadratic table specifically includes fault matching, operation mode matching, control strategy and section trend identification. Among them, the control strategy can be subdivided into control quantity and object queue, and the control method and implementation principle are set according to the differences handled by the security control device /system protection device. Constraints generally refer to the security control strategy/system protection strategy action to meet some constraints, such as DC blocking fault control strategy will generally require DC loss of power greater than the DC valve blocking cutter threshold value.

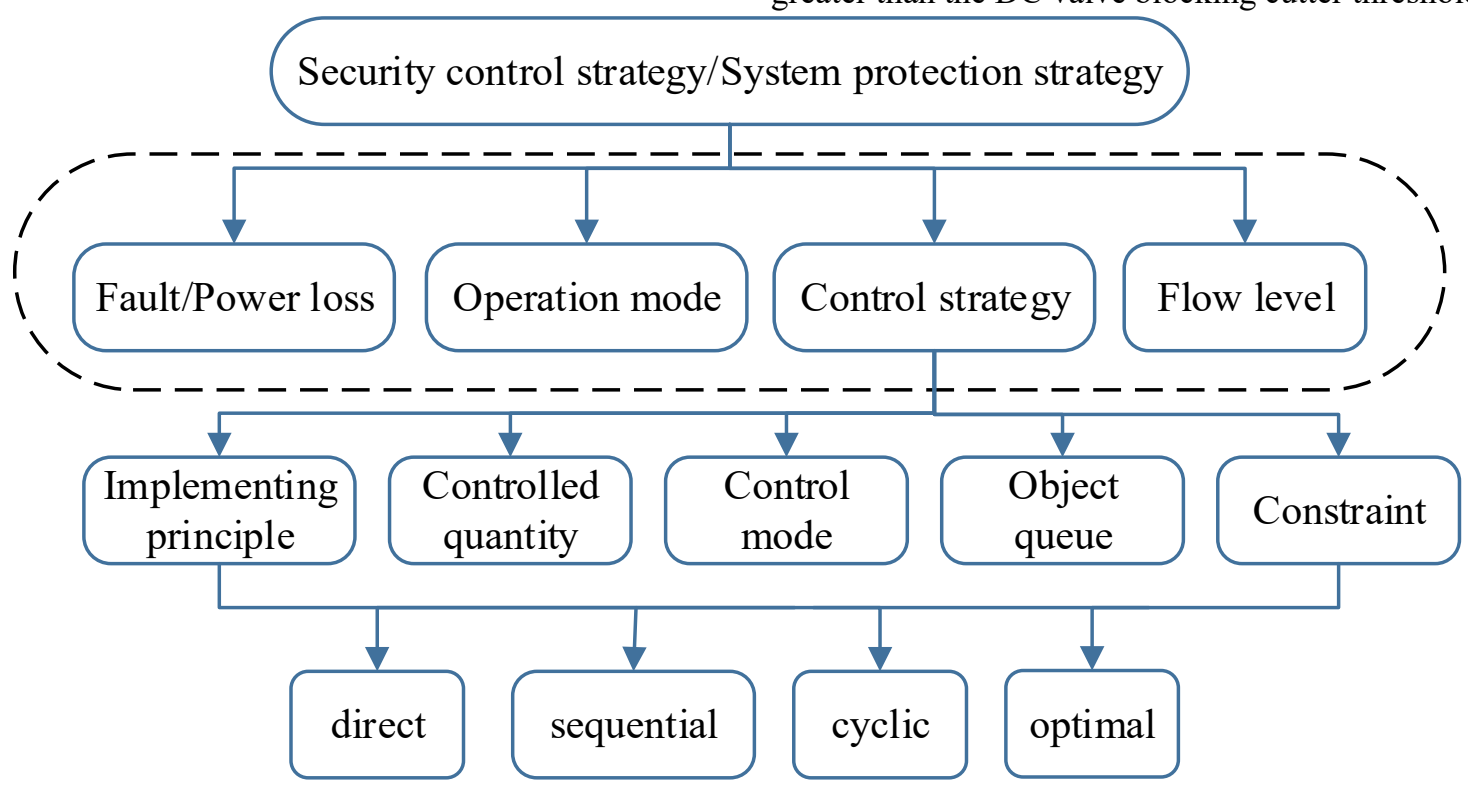

Fig. 2. Security control strategy/System protection strategy modelling. 


\subsection{High frequency cutting generator strategy modelling}

By means of comprehensive analysis on large amount of actual high frequency cutting generator strategies, the paper analyzed key factors including organizational form of the high frequency cutting generator strategy, basic control logics, mode of distribution of the controlled quantity, constructed the corresponding strategy model of the high frequency cutting generator. In order to realize the annual allocation plan of high frequency cutting generator in southwest power grid, various rounds of frequency settings, time delays, switchable configuration values and

other information can be set up.

Strategy modelling is to analyze the key elements such as strategy organization form, basic control logic, and control quantity distribution mode according to the action characteristics of the high frequency cutting generator, to establish a structured model of the control strategy, and to realize the database modelling of the control strategy. The high frequency cutting generator strategy is organized in the form of a ternary table, and the control strategy is decomposed into five basic elements, which summarizes two basic control strategy structured models by area statistics and by plant station statistics to realize the structured modelling of the defense strategy of high circumferential cutting machine. Refer to Fig 3 for detailed information.

High frequency cutting generator strategy

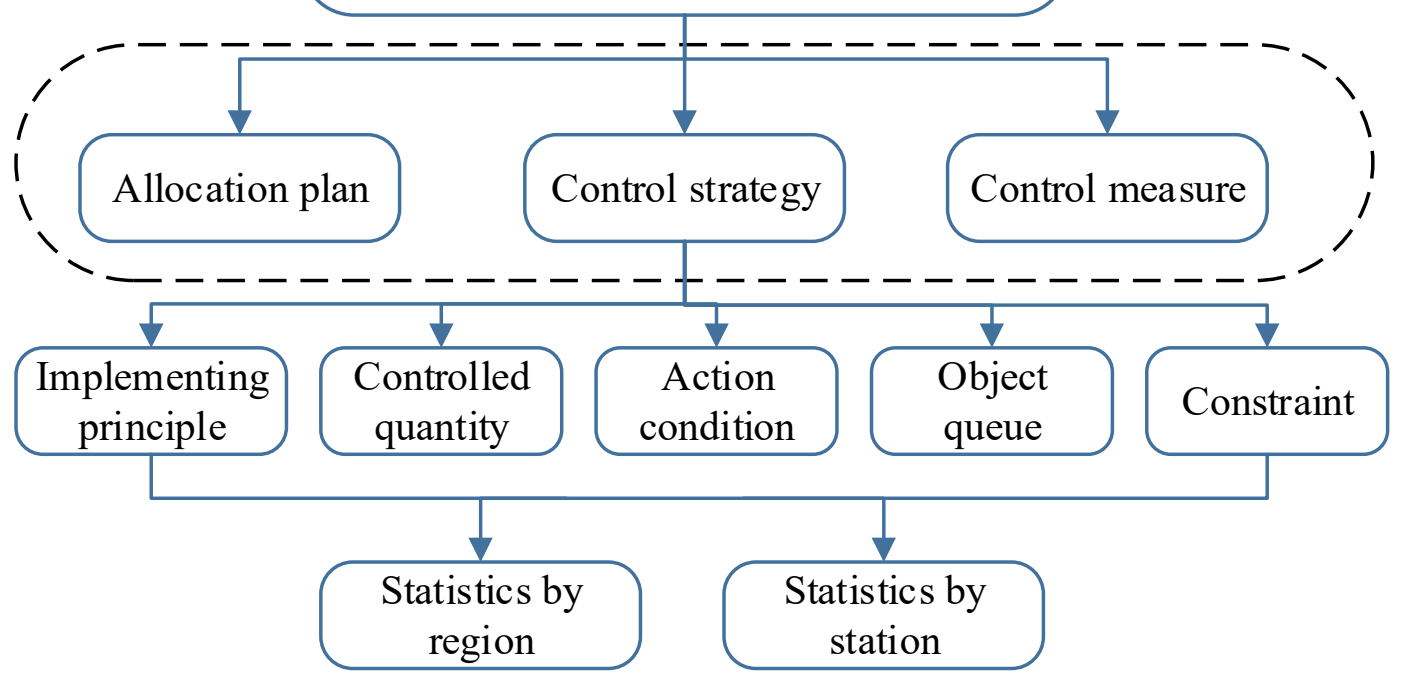

Fig. 3. High frequency cutting generator strategy modelling.

\subsection{Conflict detection}

Based on the security control strategy/system protection strategy modelling that has already been constructed, switching-off conditions of control measures and topological connection relations of various security and stability control systems will be deeply analyzed, association relations of control measure objects of various security and stability control systems will be judged, the existence of control strategy of cross configuration will be online analyzed and identified to realize strategy identification.

Based on various types of safety control strategies and online modelling of defensive lines of the high frequency cutting generator, online monitoring of cutting generator measure conflicts will be performed. Aiming at possible inter-related phenomenon of controlled objects of the same type of different types and based on real-time operation condition of power grid, conflict measure objects and conflict power values of the same type or among different types will be calculated out. Refer to Fig 4 for detailed information.

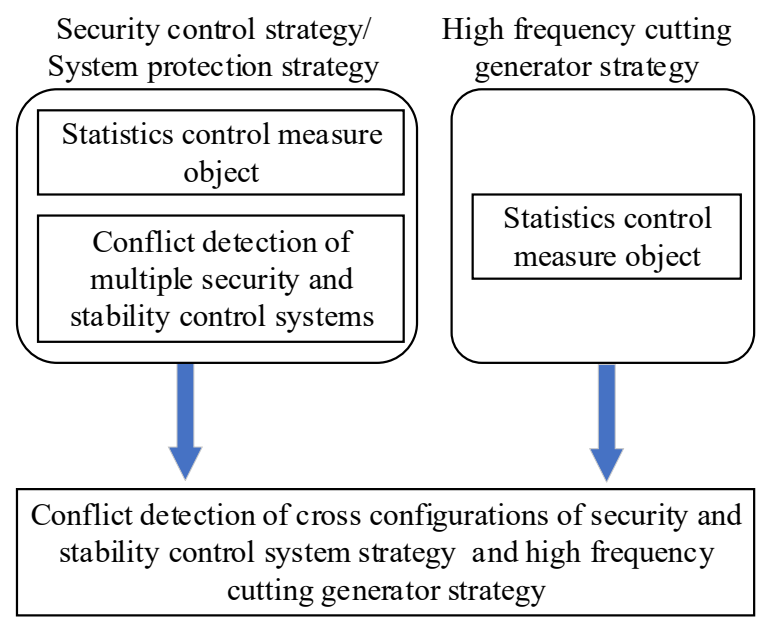

Fig. 4. High frequency cutting generator strategy modelling.

\subsection{Practicability assessment method of the second defense line}

Corresponding control strategies will be matched with onduty strategy identification and analysis according to action conditions, such as fault, operation mode, flow constraint, and the main procedure is as followed: (1) Fault 
matching. Match with the fault according to the given expected fault set and constructed in the security control strategy/system protection strategy modelling. Fault refers to the disturbance of security control strategy/system protection strategy definition, that is to say, triggering of control command must be the occurrence of specific fault; (2) Operation mode matching. As for the commissioning fault of security control device/system protection device, the paper judged if the operation mode of power grid may satisfy action conditions of the security control device/system protection device by integrating real-time operation data of power grid. Operation mode refers to the combination of switch throw in/out, device throw-in and stop and flow direction defined by security control strategy/system protection strategy. For example, maintenance of certain lines, power delivery of certain section, ring opening, upload main transformer belong to the aforementioned conditions; (3) Matching of sectional transmission flow interval. Judge the flow of section satisfying operation mode and investigate if its flow level may satisfy the specified condition for operating security control/system protection. Flow constraint refers to the range of monitoring flow value defined by security control strategy/system protection strategy. For example, sectional power is greater than 400MW and lower than 1000MW; (4) Control strategy analysis. Control strategy analysis means to analyze the control strategy, confirm the controlled quantity of various associated control measures, transform it into concrete executive strategy and distribute it to corresponding control sub-site, actuating station or execute at local site. It mainly includes basic information analysis, controlled quantity transformation and control constraint check.

Based on the real-time operating information collected by the security control device/system protection device on the basis of the identification of the on-duty strategy, such as the electrical quantity, the state of the allowable cutting pressure plate, the communication state, etc., and in combination with the offline strategy table, online calculation of the amount of control required for the onduty strategy of the security control device/system protection device in the event of a predicted fault, and comparison with the actual controllable amount of the security control device/system protection device, the evaluation result of whether the actual controllable amount can meet the implementation of the measures is given. Alarm when the amount of control measures is insufficient [23].

\subsection{Practicability assessment method of the high frequency cutting generator strategy}

First, figure out the switchable unit capacity in various rounds of single high frequency cutting generator; second, match the rounds in annual high frequency cutting generator allocation plan with various rounds of action frequency thresholds in the strategy model of high frequency cutting generator and action delay, take the round in annual high frequency cutting generator allocation plan as the standard to accumulate the switchable machine capacity in the corresponding rounds of high frequency cutting generator in the same province (district), so as to acquire total quantity of switchable machine capacity in various rounds of the annual high frequency cutting generator allocation plan in the province (district); at last, accumulate the total amount of switchable machine capacities of various provinces and districts in Branch Center to acquire the total amount of switchable machine capacity in various rounds of the overall network.

Make real-time statistics on switchable machine capacities in various rounds of the high frequency cutting generator in the overall network, compare with the required switchable machine capacity in various rounds of the high frequency cutting generator in the high frequency cutting generator allocation plan, give Online alarm and remind the dispatcher to dispose in time if the switchable machine capacity in various rounds of the high frequency cutting generator cannot satisfy the requirement on desired switchable machine capacity. Refer to Fig 5 for detailed information. 


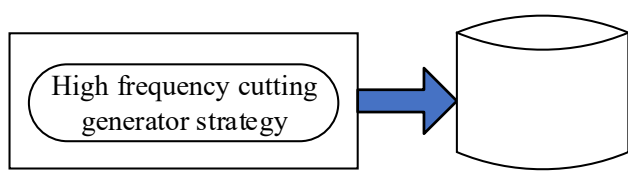

High frequency cutting generator strategy model

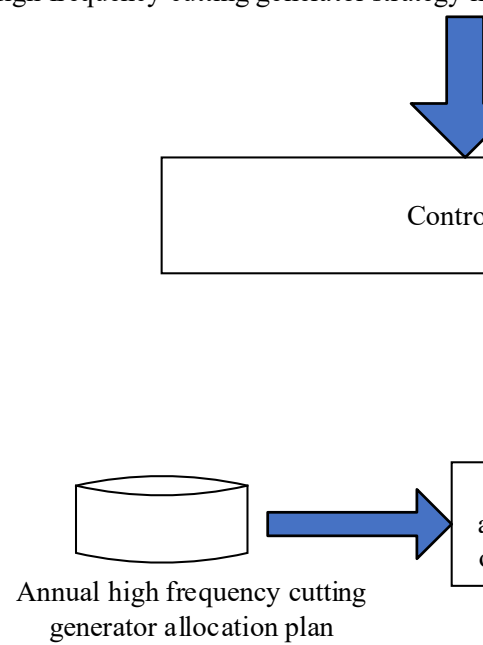

Controlled quantity recognition

Fig. 5. Frame diagram of practicability assessment method of high frequency cutting generator strategy.

\section{Situation of application}

In recent years, the hydro power in southwest power grid has been developed rapidly and is playing increasingly important role in balance of supply and demand of power grid and national energy conservation and emission reduction. The successive commissioning of a variety of UHVDC projects, but also to a certain extent to improve the power delivery and absorption of the DC power grid. Research achievements of the paper have been applied in actual projects in southwest power grid and provided reliable technical measures for solving the monitoring problem of the second and third defense line of power grid.

As the system protection analysis and decision center, southwest power grid has established security control strategy/system protection strategy model, performed rolling identification on the on-duty strategy of system protection under real-time operating condition by integrating the operation condition of security control device/system protection device directly managed by southwest power grid and uploaded by various provinces power grid, so as to timely discover if the controllable quantity of on-duty strategy is sufficient or not. Judgement of Gangudi safety control device on $500 \mathrm{kV}$ Ganshu I transmission line permanent ground fault action was taken in 2020 as an example for verification. Check strategy table to acquire capacity of the cutting generator and operate to trip off $500 \mathrm{kV}$ Lugan transmission line. The Kangding station cuts outgoing lines according to the required cutting capacity, sends the command to Danba station to cut outgoing lines, sends the command to Houziyan station to cut the unit rounds, and sends the command to Changheba station to cut the unit rounds. The Lugan line (348.4MW) was cut and the shortfall was forwarded to Kangding station (425MW). The following previously mentioned techniques such as security control strategy/system protection strategy modelling, practicability assessment method of security control strategy/system protection strategy, and crossconfiguration conflict detection facilitate the validation of system functionality.

\subsection{Security control strategy/System protection strategy modelling}

Table 1. Security control strategy/System protection strategy modelling.

\begin{tabular}{lllll}
\hline \multicolumn{1}{c}{ Operation mode } & Fault & Sectional position & $\begin{array}{c}\text { Controlled } \\
\text { quantity }\end{array}$ & $\begin{array}{c}\text { Constraint } \\
\text { condition }\end{array}$ \\
\hline $\begin{array}{l}\text { Kanggan double loop } \\
\text { operation, Gansu single } \\
\begin{array}{l}\text { loop operation, Kangshu } \\
\text { double loop operation }\end{array}\end{array}$ & $\begin{array}{l}\text { 500kv Gansu single line } \\
\text { permanent ground fault }\end{array}$ & $\begin{array}{l}\text { Gansu double loop } \\
\text { sectional } \\
\text { power }>=850\end{array}$ & $\begin{array}{l}\text { All reserved } \\
100 \mathrm{MW}\end{array}$ & None \\
\hline
\end{tabular}

As stated in the above table, during the operation period of Kanggan double loop operation, Gansu single loop operation and Kangshu double loop operation,500kv
Gansu single line permanent ground fault was detected by Gangudi security control device, and the actual power of Gansu double loop section is $873.7 \mathrm{MW}$. According to the 
constructed strategy table, the capacity of $100 \mathrm{MW}$ is required to be reserved and the desired controlling quantity is $773.7 \mathrm{MW}$. First, the outgoing lines of Gangudi will be tripped off, among which, the outgoing lines of Xinduqiao are uncontrollable and only $500 \mathrm{kV}$ Lugan line
(347MW) is controllable, and the insufficient controllable quantity (426MW) will be forwarded to Kangding for processing. Refer to Table 2 and Table 3 for detailed information about control measure modelling.

Table 2. Xinduqiao control measure modelling.

\begin{tabular}{cccc} 
& & & Unit: MW \\
\hline Execution station & Control device & Power & Priority \\
\hline Xinduqiao & Xinduqiao 1st round outgoing line & 0 & - \\
Xinduqiao & Xinduqiao 2nd round outgoing line & 0 & - \\
Xinduqiao & Xinduqiao 3rd round outgoing line & 0 & - \\
Xinduqiao & Xinduqiao 4th round outgoing line & 0 & - \\
Xinduqiao & Xinduqiao 5th round outgoing line & 0 & - \\
Xinduqiao & Xinduqiao 6th round outgoing line & 0 & - \\
Xinduqiao & Xinduqiao 7th round outgoing line & 0 & - \\
Gangudi & Lugan line & 347 & 1 \\
\hline
\end{tabular}

Table 3. Xinduqiao control measure modelling.

\begin{tabular}{|c|c|c|c|c|c|}
\hline & & & & & Unit: MW \\
\hline $\begin{array}{l}\text { Execution } \\
\text { station }\end{array}$ & $\begin{array}{l}\text { Station } \\
\text { priority }\end{array}$ & Control device & Power & Running state & Total Priority \\
\hline \multirow{3}{*}{ Danba } & \multirow{3}{*}{1} & Guodan line & 15.2 & run & $1 * 10+1=11$ \\
\hline & & Guandan line & 76.3 & run & $2 * 10+1=21$ \\
\hline & & Handan line & 11.1 & run & $1 * 10+1=11$ \\
\hline \multirow{4}{*}{ Houziyan } & \multirow{4}{*}{2} & \#1 unit & 4.3 & run & $3 * 10+2=32$ \\
\hline & & $\# 2$ unit & 0 & off & - \\
\hline & & $\# 3$ unit & 170.6 & run & $5 * 10+2=53$ \\
\hline & & $\# 4$ unit & 0.3 & run & $7 * 10+2=72$ \\
\hline \multirow{2}{*}{ Changheba } & \multirow{2}{*}{3} & $\# 1$ unit & 219.5 & run & $3 * 10+3=33$ \\
\hline & & $\# 2$ unit & 206.1 & run & $4 * 10+3=43$ \\
\hline \multirow{4}{*}{ Kangding } & \multirow{4}{*}{4} & Heding line & 47.4 & run & $1 * 10+4=14$ \\
\hline & & Bading line & 39.8 & run & $2 * 10+4=24$ \\
\hline & & Jinding line & 0 & off & - \\
\hline & & Huangkang line & 112.8 & run & $4 * 10+4=44$ \\
\hline
\end{tabular}

\subsection{Practicability assessment method of on-duty strategy}

The required controllable quantity forwarded to Kangding was $426 \mathrm{MW}$ and the execution stations are Danba, Houziyan, Changheba and Kangding. Firstly, trip off according to the priority of rounds, then the priority of stations. Priority of the control measures shall integrate the station priority and the device priority. Set the station priority as i, priority of the device is $\mathrm{j}$, and the final priority can be represented as $\mathrm{p}=\mathrm{i}+\mathrm{j} * 10$; In order of final priority, the lesser priority is taken in order of accumulation until the required control quantity is achieved. As shown in Table 4, actual controlling quantity is $619.7 \mathrm{MW}$, which satisfies the requirement of the forwarded controlling quantity $426 \mathrm{MW}$ and the strategy practicability assessment method result is that the controlled quantity is sufficient. The control strategy satisfies the requirements on control, and is in consistent with the actual result of safety control operation.

Table 4. Actual control measures.

\begin{tabular}{ccc}
\hline & & Unit: MW \\
\hline Control Device & Power & Priority \\
\hline Guodan line & 15.2 & 11 \\
Handan line & 11.1 & 11 \\
Heding line & 47.4 & 14 \\
Guandan line & 76.3 & 21 \\
Bading line & 39.8 & 24 \\
Houziyan \#1 unit & 4.3 & 32 \\
Changheba \#1 unit & 219.5 & 33 \\
Changheba \#2 unit & 206.1 & 43 \\
\hline
\end{tabular}




\subsection{Conflict Detection}

As shown in Table 3, the units of Changheba and Houziyan station serve as the objects of controllable measures of security control strategy/system protection strategy; however, regarding the third defense line, units of the aforementioned two units may also serve as the measures of the high frequency cutting generator. As stated in Section 2.3, system will judge that the units of Changheba and Houziyan all belong to the objects of control measures of the second and third defense line simultaneously, acquire the existence of cross configuration in the aforementioned units, remind operational and dispatching personnel that operational risks of reduced controllable measures of the high frequency cutting generator might be caused after the 2nd defensive line tripping off the aforementioned certain units.

\section{Conclusion}

In this paper, the proposal of the second and third defense line of risk identification function of the UHVDC sending grid is closely integrated with the security and stability needs of the southwest power grid, and is a powerful complement to the existing the $\mathrm{AC} / \mathrm{DC}$ coordinated control system. Based on the existing security control strategy/system protection strategy model and the new High frequency cutting generator strategy model, and based on the conflict detection of the second and third defense line, combined with the real-time operating conditions of the power grid statistics, it provides more comprehensive risk identification results to dispatching operators for timely detection of security hazards and potential risks in the power grid operation to ensure the safe and stable operation of the power grid. On this basis, according to the practicability assessment method result of the second and third defense line, further analysis can be launched to provide aid decision making of precaution and pre-control.

\section{Acknowledgements}

This work was funded by Southwest China Electric Power Control Center (The Science and Technology Project of "Research on the key technologies of whole network key elements modelling of AC/DC coordinated control system in southwest power grid of china", Contract No.: SGSW0000DKJS2000105).

\section{References}

1. CHEN Gang, DING Lijie, LI Min.(2018) Stability characteristics of southwest China power grid after asynchronous interconnection.J. Power System Protection and Control., 46(7):76-82.

2. CHEN Guoping, LI Mingjie, XU Tao.(2018) System protection and its key technologies of UHV AC and DC power grid .J.Automation of Electric Power Systems.,42( 22) :2-10.
3. DONG Yu, ZHANG Xin, YU Rui.(2018) Stability control and system protection scheme for power grid with hydropower pool and multi-DC weak sendingend .J. Automation of Electric Power Systems., 42(22):19-25.

4. ZHU Lin, HE Zhiyuan, WU Xueguang.(2018) Influence of additional control strategy of back-toback VSC-HVDC on system stability .J. Power System Technology., 42(8):2519-2527.

5. ZHENG Chao, LIU Bosi, BAI Shibin.(2018) Study on the dynamic characteristic and stability control measures for asynchronous interconnection regional power grid with VSCHVDC.J. Journal of Global Energy Interconnection.,1(2):129-136

6. DONG Xijian,LUO Jianbo,LI Xueming.(2018) Research and application of frequency emergency coordination and control technology in hybrid AC / DC power grids.J . Power System Protection and Control.,46(18):59-66.

7. ZHENG Chao, MA Shiying, SHEN Xuhui.(2017) Definition,Connotation and Form of Strong HVDC and Weak $\mathrm{AC}$ and Countermeasures for Stable Operation of Hybrid Power Grid.J. Power System Technology.,41(8):2491-2498.

8. LI Chao,YAN Yunsong,XIONG Jun.(2020) Design and Application of AC/DC Coordinated Control System in Southwest power grid of China.J. Automation of Electric Power Systems.,44(8):200206.

9. WANG Yanjun,LING Weijia,LI Zhaowei.(2018) Activesplitting strategy of multi-infeed DC receivingend gridwith severe faults.J.Automation of Electric Power Systems.,42(24):86-91.

10. LUO Yazhou,CHEN Dezhi,LI Yiqun.(2018) Design of system protection scheme for North China multiUHV AC and DC strong coupling large receiving-end power grid.J.Automation of Electric Power Systems., 42(22):11-18.

11. WEN Yuqi. (2019)A Frequency Response Analysis Method for Wind Power System Based on Data DriVen-Physical Model Fusion.J. Guangdong Electric Power.,32(9):167-176.

12. LI Donghui,ZANG Xiaoming,JU Ping.(2019)The improved model and parameter estimation for frequency response of power system.J. Electric Power Engineering Technology, 2019,38(5):85-90.

13. CHEN Xinghua,LI Feng, CHEN Rui.(2020) Risk assessment of power grid operation considering second and third defense line of security and stability .J. Power System Protection and Control., 48(4):159-166

14. LUO Jianbo, DONG Xijian,CUI Xiaodan.(2018) Discussion on reliability of large scale security and stability control system .J. Power System Protection and Control.,46(8):159-166

15. LI Desheng, LUO Jianho(2016)Typical design of security and stability control system for UHVDC transmission.J. Autom ation ofElectricPower 
Systems.,40(14):151-157

16. SHEN Fengjie,CAI Hongquan,XU Hongtao.(2017) Design of collaborative monitoring and control system for emergency control device used for province-district two-level power grid.J. Power System Protection and Control., 45(6):126-132

17. LI Ling, SUN CaiFeng, GU Jianhui . (2015) Research and Development of Guangxi Power Grid Security and Stability Control Management System Based on PCS-9000 Platform .J . Power System and Clean Energy.,31(4):1-5

18. SHI Zheng, XU Yin, WU Xiangyu. (2020)Assessment of system protection strategy and aided decision scheme for AC/DC hybrid power systems .J . Electric Power Automation Equipment., 40(4):25-31

19. WANG Yang, XIANG Zhen, ZHANG Gang. (2020) Design and Application of Integrated Monitoring and Early Warning System for Defense Line of High Frequency Cutting Generator in Regional Power Grid.J. Power System and Clean Energy.,36(8):28-37

20. ZHAO Yan, ZHANG Wenchao, LI Yiqun.(2015) Research on the general control strategy of power system tuning method.J.Power System Protection and Control., 43(4):102-107

21. WU Guoyang, SONG Xinli, TANG Yong.(2012) Modelling of Security and Stability Control System for Power System Dynamic Simula-tion.J. Automation of Electric Power Sys-tems.,36(3):71-75

22. SHAO Wei, ZHOU Xiaoning, WANG Shengming. (2014) An Object-Oriented Stability Control Strategy Modelling Method.J. Power System and Clean Energy.,30(9):19-25

23. WANG Shengming, XU Tanshan,CHEN Gang.(2019) Assessment method of Duty Strategy for Security and Stability Control System in Power Grid.J. Automation of Electric Power System.,43(24):126-133 